\title{
Effect of abnormal liver function test on maternal and perinatal outcome in pregnancy: observational study
}

\author{
Rashmi Tripathi, Madhuri Brahmane*, Sapna Bajaj Jain
}

Department of Obstetrics and Gynecology, L. N. M. C., J. K. Hospital, Bhopal, Madhya Pradesh, India

Received: 12 July 2020

Accepted: 20 August 2020

\section{*Correspondence:}

Dr. Madhuri Brahmane,

E-mail: drmadhuribrahmane@gmail.com

Copyright: () the author(s), publisher and licensee Medip Academy. This is an open-access article distributed under the terms of the Creative Commons Attribution Non-Commercial License, which permits unrestricted non-commercial use, distribution, and reproduction in any medium, provided the original work is properly cited.

\begin{abstract}
Background: The present study was conducted with the objective to assess the spectrum of liver disease in pregnancy, and its course and effect on maternal and fetal outcomes.

Methods: The present study was conducted as a prospective follow up study in the department of Obstetrics and Gynaecology, J. K. Hospital for a period of 1 year. The pregnant women between the ages of 18-35 years presenting with symptoms suggestive of underlying liver disease were selected. Socio demographic details and clinical history was obtained from all the participants and they were subjected to liver function test (LFT). All patients were followed till 2 weeks post-partum period. The maternal and fetal outcomes were noted.

Results: The following results were obtained: pregnancy-induced hypertension (PIH) was the most common cause of abnormal LFT (46.66\%), about $57.5 \%$ patients delivered at term, $63.3 \%$ patients delivered vaginally, mostly cases delivered a term healthy neonate between 2.5-3.0 kg weight with Apgar score $>7$ at 5 minutes after birth and maternal complications were seen in $10.82 \%$ cases.

Conclusions: Our study shows that though liver disease is uncommon in Indian pregnant women, but it is associated with high maternal and perinatal morbidity. A high index of suspicion of liver disease, early diagnosis, prompt referral to a higher centre when required, appropriate supportive management, and a proactive policy of early delivery when indicated may improve the maternal and fetal outcomes in pregnant women with liver disease. Thus LFT should be conducted as a routine investigation in all pregnant females during first and second trimester.
\end{abstract}

Keywords: Acute fatty liver of pregnancy, Hyperemesis gravidarum, Liver function test, Pre-eclampsia

\section{INTRODUCTION}

Liver disease is a rare complication of pregnancy affecting approximately $3 \%$ to $5 \%$ of all pregnancies. ${ }^{1}$ Liver involvement in pregnancy can be of 3 types i.e. liver disease as a consequence to pregnancy, liver disease coincidental to pregnancy and pregnancy in patients with pre-existing liver disease. ${ }^{2}$ Liver diseases which can be due to pregnancy as a consequence of changes in pregnancy include intrahepatic cholestasis of pregnancy (ICP), acute fatty liver of pregnancy (AFLP) and, hemolysis, elevated liver enzymes and low platelets count (HELLP) syndrome. Apart from these, liver abnormalities are often encountered in patients with pre-eclampsia (PE) and hyperemesis gravidarum (HG). Coincidental or preexisting liver disease include acute and chronic viral hepatitis, cirrhosis of liver, vascular alterations such as Budd-Chiari syndrome (BCS), drug induced hepatotoxicity, autoimmune liver diseases, and metabolic disorders. ${ }^{3}$ These liver disorders in pregnancy may adversely affect maternal and fetal outcome.

Physiological alterations in pregnancy may mask the liver disease or the patients may present with mild nonspecific symptoms such as nausea, vomiting and abdominal pain. Slight physiological alterations of liver function tests are observed in pregnancy where increase in the level of alkaline phosphatase and clotting factor with decrease in 
the level of antithrombin III and protein S, serum albumin and total proteins are observed, however, level of liver transaminase, serum bilirubin level and prothombin time remain unchanged. ${ }^{4}$ Thus elevations in aminotransferases or gamma-glutamyl transpeptidase (GGTP) signify pathology, and should prompt a search for disease diagnosis of liver disease during pregnancy.

There is insufficient information about the frequency, etiological profile, outcome, and management guidelines for pregnancy-related liver disease in India. Therefore the present study was conducted with the objective to assess the spectrum of liver disease in pregnancy, and its course and effect on maternal and fetal outcomes.

\section{METHODS}

The present study was conducted as a prospective follow up study in the Department of Obstetrics and Gynecology, Laxmi Narayan Medical College and associated J. K. Hospital, Bhopal for the period of 1 year i.e. from 01 January 2019 to 30 December 2019. All pregnant women attending the outdoor department or admitted between the age group of 18-35 years were screened over the study period. Inclusion criteria was pregnant females between 18-35 years presenting with pruritis, abdominal pain, jaundice, fever, pedal edema, raised blood pressure, bleeding disorder, hepatosplenomegaly, known case of portal hypertension, hepatitis, cirrhosis alcoholism and gall stone disease, history of cholestasis, pre-eclampsia and eclampsia in previous pregnancy; or any liver disease under current treatment, normal asymptomatic patients were excluded from the study.

All patients included were then subjected to liver function tests after obtaining informed consent. The protocol was approved by the ethics research committee of the institute. Apart from LFT, viral markers hepatitis B surface antigen (HBsAg), hepatitis A virus (HAV), hepatitis E virus (HEV), hepatitis C virus (HCV) and other viral marker, ultrasonography (USG) of hepatobiliary system were also done if indicated. Patients with abnormal LFT reports were observed for complications, and patients managed accordingly by standard management protocols.

Fetomaternal outcomes was noted and patients were prospectively followed up till two weeks post-partum. A total of 8091 females attended outpatient department (OPD) and inpatient department (IPD) during the study period, out of them, 180 females fulfilling inclusion criteria were screened and liver function tests were conducted among them. Screening was done, 136 females were observed to have abnormal liver function; of them, 16 patient lost to follow-up, hence excluded from study (4 of hyper emesis, 2 of jaundice and 10 of pregnancy induced hypertension-PIH) in statistical data analysis. Maternal deaths were noted in 2 cases to severe PIH with disseminated intravascular coagulation (DIC) and other with multiorgan failure in post-partum period. Thus the present study was conducted on a total of 120 patients.

\section{Statistical analysis}

Data was compiled using Microsoft Excel and analyzed using IBM Statistical Package for the Social Sciences (SPSS) version 20 software.

\section{RESULTS}

The incidence of liver disease during pregnancy in present study was $1.68 \%$. The study was conducted on 120 pregnant females between 18 to 35 years with mean age of $25.3 \pm 4.8$ years.

Majority of patients in present study belonged to 25 to 29 years of age $(49.17 \%)$ followed by $47(39.17 \%)$ cases belonging to 20-24 years of age. About $65 \%$ females were nulliparous whereas $19.2 \%$ were parity 1 . Most common presenting complaints was oedema observed in 22 $(18.33 \%)$ cases followed by itching all over body noted in $19(15.8 \%)$ cases. Vomiting was presenting complaints in $10(8.3 \%)$ cases with hyperemesis gravidarum presenting in first trimester of pregnancy. About 4 patients $(3.3 \%)$ presented with convulsions, blurring of vision and altered sensorium. Only $1(0.8 \%)$ female presented with acute abdominal pain. (Table 1).

Table 1: Distribution according to baseline variables.

\begin{tabular}{|lll|}
\hline $\begin{array}{l}\text { Baseline } \\
\text { variables }\end{array}$ & $\begin{array}{l}\text { Frequency } \\
(\mathbf{n = 1 2 0})\end{array}$ & Percentage \\
\hline Age group (years) & & \\
\hline$<20$ & 06 & 5.0 \\
\hline $20-24$ & 47 & 39.17 \\
\hline $25-29$ & 59 & 49.17 \\
\hline $30-34$ & 8 & 6.66 \\
\hline Parity & & \\
\hline 0 & 78 & 65 \\
\hline 1 & 23 & 19.2 \\
\hline 2 & 8 & 6.6 \\
\hline 3 or more & 11 & 9.2 \\
\hline Symptoms & & \\
\hline Vomiting & 10 & 8.3 \\
\hline Oedema & 22 & 18.3 \\
\hline Itching & 19 & 15.8 \\
\hline High BP & 20 & 16.7 \\
\hline Convulsion & 4 & 3.3 \\
\hline Jaundice & 4 & 3.3 \\
\hline $\begin{array}{l}\text { Diminished fetal } \\
\text { movement }\end{array}$ & 11 & 9.2 \\
\hline Abdominal pain & 1 & 0.8 \\
\hline Others & 29 & 24.2 \\
\hline & & \\
\hline
\end{tabular}

Pregnancy induced hypertension was the most common cause of abnormal liver function test in pregnancy contributed $46.66 \%$ of all cases followed by viral hepatitis $(20.83 \%)$ and cholestasis $(19.16 \%)$. Out of 23 cases of cholestasis, cholecystectomy was done in 1 case in women at 8 month of gestation period. Hyperemesis gravidarum 
was noted in $6.66 \%$ of cases while gall stones accounts for $3.33 \%$ cases. Drug induced hepatitis was observed in $2.5 \%$ cases. Other causes included fever with deranged liver function test (Figure 1).

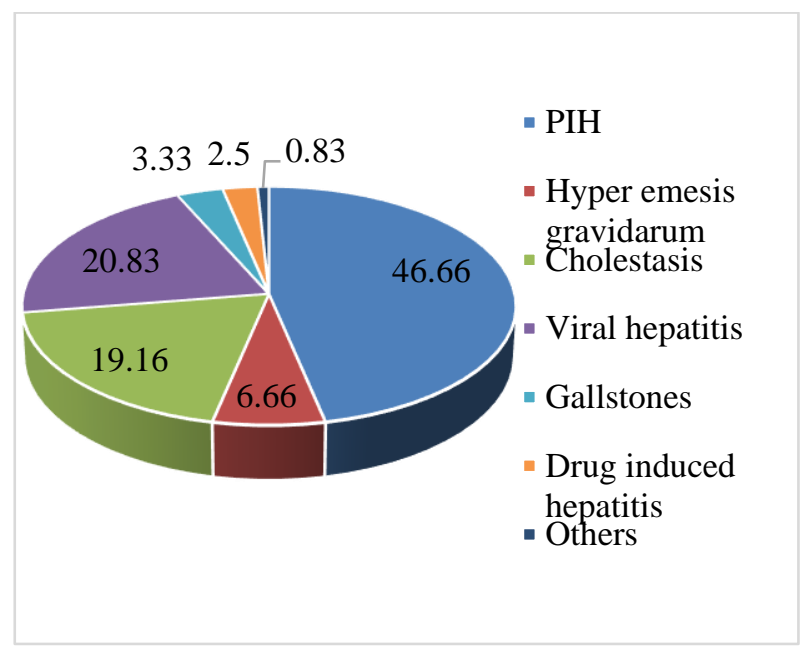

Figure 1: Distribution of pregnant females according to cause of abnormal liver function test.

History of liver disease in previous pregnancy was observed 18 cases, of them, 6 patients $(5 \%)$ gave history of high blood pressure, 4 patients $(3.33 \%)$ gave history of jaundice in previous pregnancy, history of itching was present in $4(3.33 \%)$ patients, 3 patients $(2.50 \%)$ gave history of gall stones and 1 patient $(0.83 \%)$ had history of eclampsia during previous pregnancy.

About $76(63.3 \%)$ patients had normal vaginal deliveries, of them, 63 patients had spontaneous vaginal delivery whereas induction was require in 13 cases. Caesarean section was done in $36.7 \%$ cases (Table 2). Most of the patients with abnormal liver function test delivered at term whereas preterm delivered were observed in $18(15 \%)$ patients which were mostly due to severe PIH.

Table 2: Distribution according to mode of delivery.

\begin{tabular}{|lll|}
\hline Mode of delivery & $\begin{array}{l}\text { Frequency } \\
(\mathbf{n = 1 2 0})\end{array}$ & Percentage \\
\hline Vaginal & 76 & 63.3 \\
\hline Caesarean & 44 & 36.7 \\
\hline
\end{tabular}

Maternal complications were observed in $10.82 \%$ of all cases. Most common complication was abruption placentae $(4.16 \%)$ followed by PPH and sepsis observed in $3.33 \%$ and $1.7 \%$ respectively. DIC was observed in only $1(0.83 \%)$ patient only. Cholecystectomy was done in one case of cholestasis and maternal deaths were noted in 2 cases which were attributed to severe PIH associated with DIC and multi-organ failure respectively (Table 3).

Fetal outcome in majority of cases was alive and healthy at term $(57.5 \%)$ whereas $18(15 \%)$ cases had preterm live births. Intrauterine growth restriction was observed among
$27(22.5 \%)$ cases and intrauterine death was seen among 6 $(5.0 \%)$ cases (Table 4$)$.

Table 3: Distribution according to maternal complications.

\begin{tabular}{|lll|}
\hline Complications & $\begin{array}{l}\text { Frequency } \\
(\mathbf{n}=13)\end{array}$ & Percentage \\
\hline $\begin{array}{l}\text { DIC (post-partum } \\
\text { death) }\end{array}$ & 1 & 0.83 \\
\hline $\begin{array}{l}\text { Multi-organ failure } \\
\text { (post-partum collapse) }\end{array}$ & 1 & 0.83 \\
\hline Sepsis & 2 & 1.7 \\
\hline PPH & 4 & 3.33 \\
\hline Abruptio placentae & 5 & 4.16 \\
\hline Total & 13 & 10.82 \\
\hline
\end{tabular}

Table 4: Distribution according to fetal outcome.

\begin{tabular}{|lll|}
\hline Fetal outcome & $\begin{array}{l}\text { Frequency } \\
(\mathbf{n = 1 2 0})\end{array}$ & Percentage \\
\hline Preterm & 18 & 15 \\
\hline Term (normal healthy) & 69 & 57.5 \\
\hline Term IUGR & 27 & 22.5 \\
\hline IUD & 06 & 5.0 \\
\hline
\end{tabular}

In present study, about $31.6 \%$ cases were low birth weight $(<2.5 \mathrm{~kg})$ which was due to IUGR or preterm delivery and Apgar score at 5 min was $<4$ in $7.9 \%$ cases i.e. mostly among neonates born to mothers with pregnancy induced hypertension (Table 5).

Table 5: Distribution according to birth weight and Apgar score at 5 minute.

\begin{tabular}{|c|c|c|}
\hline & $\begin{array}{l}\text { Frequency } \\
(n=114)\end{array}$ & Percentage \\
\hline \multicolumn{3}{|c|}{ Birth weight (kg) } \\
\hline $1.5-2.5$ & 36 & 31.6 \\
\hline 2.5-3.0 & 62 & 54.4 \\
\hline$>\mathbf{3 . 0}$ & 16 & 14.0 \\
\hline \multicolumn{3}{|c|}{ Apgar score at 5 min } \\
\hline$<4$ & 09 & 7.9 \\
\hline 4-7 & 32 & 28.1 \\
\hline$>7$ & 73 & 64 \\
\hline
\end{tabular}

\section{DISCUSSION}

Liver diseases in pregnancy is associated with various complications among both mother and fetus. The present study documented incidence of liver disease in $1.68 \%$ in pregnancy. However Rathi et al in their study reported much lower prevalence $(0.9 \%)$ of liver disease in pregnancy. ${ }^{2}$ Mishra et al also documented $0.9 \%$ incidence of liver disease. ${ }^{5}$ The observed discrepancy in incidence rate of liver disease between present study and reference study could be due to difference in inclusion criteria. All the patients with abnormal liver function tests weather 
acute or chronic were included in our study whereas Mishra et al excluded chronic liver disease patients.

Maximum cases in present study belonged to 25-29 years of age. These findings were in concordance to study by Sumangali et al in which Majority of the patients were in the age group 21-30 years and were primigravida. ${ }^{6}$ This finding was corresponds to Dang et al. ${ }^{7}$ Present study documented liver disease in maximum $(65 \%)$ nulliparous females or primigravida females. Dang et al also reported similar findings in which $72.3 \%$ females were primigravida. $^{7}$ Positive past history of hypertension was seen in $5 \%$ of all patients with pregnancy induced hypertension. This was similar to study by Yelmiziatun et al, in which about $8.3 \%$ females with past history of PIH developed preeclampsia in current pregnancy. ${ }^{8}$

Patients with liver disease in pregnancy usually present with non-specific symptoms. About $12.5 \%$ patients with $\mathrm{PIH}$, hepatitis B and all cases of gallstones presented with non-specific symptom such as vomiting and itching. These cases were diagnosed on the basis of past history, examination and clinical investigation. Itching without rash was the chief complaints among all patients with IHCP. Similar findings were noted by Ruqqia et al where all patients (30\% mild and $70 \%$ severe) had itching as presenting symptom. ${ }^{9}$ Similar to our study, Bolukbas et al also observed that all pregnant women with gallstones were asymptomatic. ${ }^{10}$ One female of cholestasis presented with acute abdominal pain at 8 month of gestation and aminotransferase levels were also increased; immediate cholecystectomy was conducted in such case.

Vaginal deliveries were conducted in $63.3 \%$ of patients with abnormal LFT whereas remaining $36.7 \%$ cases with liver disease underwent caesarean section. Vaginal deliveries were conducted in $34(57.62 \%)$ cases with PIH. This corresponds to study of Singhal et al and Kenyon et al in which $32 \%$ and $36 \%$ patients respectively underwent caesarean section. ${ }^{11,12}$ Cesarian section rate in cases of liver diseases were comparatively higher $(55.2 \%)$ in a study by Mbachu et al. ${ }^{13}$ Maternal complications were observed $10.82 \%$ in our study. Maternal mortality was observed in $2(1.7 \%)$ cases due to DIC and multiorgan failure respectively. Rathi et al however observed a higher maternal mortality of $20 \% .^{2}$ This is because of difference in referral pattern in various institutes. In contrast Ch'ng et al reported no maternal mortality in their study. ${ }^{14}$ Abruptio placenta was the most common maternal complication in our study which was supported by a similar study done by Stirrat et al where abruption placenta was observed in $15 \%$ cases. $^{15}$

Majority of the patients in present study i.e. $57.5 \%$ delivered at term whereas all the mother with PIH delivered preterm (15\%). This corresponds with study of Ch'ng et al where median age at delivery was 38 weeks. ${ }^{14}$ Dang et al in their study also documented delivery at term in $76.6 \%$ patients with abnormal LFT. ${ }^{7}$
Fetal outcome was alive and healthy at term in majority of cases with liver dysfunction i.e. in $57.5 \%$. Perinatal mortality was observed in $5 \%$ cases whereas intrauterine growth restriction and preterm birth were observed among $22.5 \%$ and $15 \%$ cases respectively in our study. Similar findings were depicted by Singhal et al, where incidence of IUGR was documented as $23 \%$ and IUD as $28 \% .^{11}$ However Rathi et al documented much higher perinatal mortality rate of $44.44 \%$ as compared to present study. ${ }^{2}$ Birth weight is an important predictor of perinatal mortality and morbidity. Birth weight is less affected in cases of liver dysfunction when proper antenatal care is given. All patients with PIH delivered low birth weight babies < $2.5 \mathrm{kgs}$. Similar findings were documented by Kumar et al in which about $50 \%$ of new born were having birth weight $1.5-2.5$ kgs. ${ }^{16}$ Similarly Ussanee et al and Singhal et al reported higher prevalence of low birth weight in women with preeclampsia. ${ }^{11,17}$ Hyperemesis gravidarum was not associated with low birth weight in present study, however contrasting results were obtained by Veenendaal et al, prevalence of low birth was $6.4 \%$ among women with hyperemesis gravidarum. ${ }^{18}$ Apgar score at 5 minutes was severely depressed in $7.9 \%$ cases whereas it was between 4 to 7 in $28.1 \%$ cases in present study. Women with PIH and cholestasis had low Apgar score and thus they were admitted to NICU.

The present study had certain limitations. Mother and neonates were followed up only till 2 weeks, thus late complications associated with liver disease could not be studies.

\section{CONCLUSION}

Our study shows that though liver disease is uncommon in Indian pregnant women, it is associated with high maternal and perinatal morbidity. PIH-associated liver dysfunction, AFLP and viral hepatitis are serious conditions. A high index of suspicion of liver disease, early diagnosis, prompt referral to a higher centre when required, appropriate supportive management, and a proactive policy of early delivery when indicated may improve the maternal and fetal outcomes in pregnant women with liver disease. Thus LFT should be conducted as a routine investigation in all pregnant females during first and second trimester.

\section{Funding: No funding sources \\ Conflict of interest: None declared \\ Ethical approval: Not required}

\section{REFERENCES}

1. Hay JE. Liver disease in pregnancy. Hepatol. 2008;47(3):1067-76.

2. Rathi U, Bapat M, Rathi P, Abraham P. Effect of liver disease on maternal and fetal outcome-a prospective study. Ind J Gastroenterol. 2007;26(2):59.

3. García-Romero CS, Guzman C, Cervantes A, Cerbón M. Liver disease in pregnancy: Medical aspects and 
their implications for mother and child. Ann Hepatol. 2019;18(4):553-62.

4. Mitra AK, Patki PS, Mitra SK. Liver disorder during pregnancy and their management. Antiseptic. 2008;105(4):193-6.

5. Mishra N, Mishra VN, Thakur P. Study of abnormal liver function test during pregnancy in a tertiary care hospital in Chhattisgarh. J Obstet Gynecol India. 2016;66(1):129-35.

6. Sumangali PK, Kurian S. Study of abnormal liver function tests in pregnancy in a tertiary centre in North Kerala. Int J Res Med Sci. 2017;5:5193-6.

7. Dang A, Agarwal N, Bathla S,Sharma N, Balani S. Prevalence of liver disease in pregnancy and its outcome with emphasis on obstetric cholestasis: an Indian scenario. J Obstet Gynecol India. 2010;60(6):413-8.

8. Yelmizaitun O, Jeriah I, Huraini H, Mazlina MN, Zailina TN, NorashidahA, et al. Fetal-maternal outcome among pregnancy induced hypertension mothers attending klinik kesihatan rantau panjang in 2010 . Available at: http://www.jknkelantan.moh.gov.my/v3/uploads/file s/pdfs/khc2011/ OP_24.pdf. Accessed on: 14 January 2016.

9. Sultana R, Sarwar I, Fawad A, Noor S, Bashir R. Neonatal outcome in obstetric cholestasis patients at Ayub Teaching Hospital Abbottabad. J Ayub Medical College Abbottabad. 2009;21(4):76-8.

10. Bolukbas FF, Bolukbas $\mathrm{C}$, Horoz $\mathrm{M}$, Ince AT, Uzunkoy A, Ozturk A, et al. Risk factors associated with gallstone and biliary sludge formation during pregnancy. J Gastroenterol Hepatol. 2006;21(7):1150-3.

11. Singhal S, Deepika A, Nanda S. Maternal and perinatal outcome in severe pre-eclampsia and eclampsia. South Asian Federation of Obstetrics and Gynecology. 2009;1(3):25-8.

12. Kenyon AP, Piercy CN, Girling J, Williamson C, Tribe RM, Shennan AH. Obstetric cholestasis, outcome with active management: a series of 70 cases. BJOG. 2002;109:282-8.

13. Mbachu II, Udigwe GO, Okafor CI, Umeonunihu OS, Ezeama C, Eleje GU. The pattern and obstetric outcome of hypertensive disorders of pregnancy in Nnewi, Nigeria. Niger J Med. 2013;22(2):117-22.

14. Ch'Ng CL, Morgan M, Hainsworth I, Kingham JGC. Prospective study of liver dysfunction in pregnancy in Southwest Wales. Gut. 2002;51(6):876-80.

15. Murphy DJ, Stirrat GM, Heron J. (2002). The relationship between Caesarean section and subfertility in a population-based sample of 14541 pregnancies. Human Reproduction. 2002;17(7):19147.

16. Kumar S, Bansal D, Hota D, Jain M, Singh P, Pandey BL. (2014). Assessment of clinical outcomes and prescribing behavior among inpatients with severe preeclampsia and eclampsia: an Indian experience. Indian J Pharmacol. 2014;46(1):18.

17. Veenendaal MV, van Abeelen AF, Painter RC, van der Post JA, Roseboom TJ. (2011). Consequences of hyperemesis gravidarum for offspring: a systematic review and meta-analysis. BJOG: Int $\mathbf{J}$ Obstet Gynaecol. 2011;118(11):1302-13.

Cite this article as: Tripathi R, Brahmane M, Jain SB. Effect of abnormal liver function test on maternal and perinatal outcome in pregnancy: observational study. Int J Reprod Contracept Obstet Gynecol 2020;9:4063-7. 